\title{
A Persistent Cold-Outbreak in the Far East Related to the Blocking Situation
}

\author{
By K. Suda \\ Forecast Section, Central Meteorological Observatory, Tokyo \\ (Manuscript received 25 April 1956)
}

\begin{abstract}
A case study is made on the so-called Northeasterly pressure pattern accompanied by persistent cold-outbreak over the Far East. The period of investigation covers late September and early October 1954, when this peculiar pattern appeared with unusual distinctness. It is found that an intense cold vortex of Arctic origin, which is displaced southward to northeast Siberia in the course of world-wide decline of zonal index, gives rise to a strong cold air advection eastward along its southern margin. This cold advection is responsible to the establishment of the Northeasterly pattern and continues until the great store of cold air trapped by a blocking high is exhausted. The nature of cold vortex as to its vertical extent and its successive formation in lower latitudes is described. Also, the role of the strong westerlies as the generator of the cold air advection is discussed.
\end{abstract}

\section{§ 1. Introduction}

In the Far East, cold-outbreaks ordinarily take place following the passage of pressure troughs in the same way as in other parts of the world. In such occasions temperature may drop abruptly, sometimes to a considerable degree below normal, but the cold spell usually does not last long and, a couple of days later, temperature is used to resume its seasonal normal. Fair weather is also a common accompaniment of this type of coldoutbreaks, except for the snow shower on the Japan Sea side in winter.

On other less frequent occasions, however, the coldness brought about by the passage of a trough is intense and persists rather long, sometimes for a week or more, even when the trough is not of any considerable strength. Weather is invariably unsettled in such cases day after day, especially along the southern coast of Japan making the chill more intolerable. On the surface synoptic chart, this type of cold-outbreak is characterized by a wedge of high pressure extending from northern Manchuria through Japan Sea toward the northeast Japan with a stationary front extending in west-to-east direction off the Pacific coast. As the prevalence of northeasterly wind over the middle and southwestern part of Japan constitutes the characteristic feature of this weather situation, it is termed the "Northeasterly" situation of pressure pattern by Japanese meteorologists.

In spite of the peculiarity it presents on the synoptic maps and of its important effect upon various social activities, such a weather situation is not always easy to forecast on the extended-range basis. This is mainly due to the fact that the formation of the Northeasterly pattern is in no close relationship with the strength of passing trough and the usual forecasting procedure of tracing them and evaluating their strength on the daily synoptic maps is apt to give a poor result. Furthermore, once formed over the Fast East, this pressure pattern stagnates there showing slight change, and then becomes vague very gradually, making the forecast of its dissipation difficult.

In the present writer's view, such a conspicuous and persistent weather condition must represent a certain phase of the general circulation of the atmosphere and any appropriate method of its forecast should be sought for only by studying the development of not local but hemispherical pressure distribution. In order to elucidate the mechanism governing the formation and persistence of the Northeasterly situation and to get a clue for its forecast, a pronounced case of it, which 
appeared in October 1954, is studied in this paper, placing a special emphasis on the analysis of northern hemishere upper level maps.

\section{§ 2. Development of pressure pattern and temperature trend in the fall of $\mathbf{1 9 5 4}$}

In September 1954, hot summer weather dominated Japan with unusual persistence, and as July of the same year is characterized by an abnormal coolness, it was much talked about the "delay" of seasonal march for one month. But, after the typhoon Marie, which moved northeastward along the Japan Sea coast and crossed Hokkaido inflicting a catastrophic ferry-boat accident, had passed away to the Okhotsk Sea on 26 , the temperature over Japan began to fall. Especially, following the passage of a cyclone,

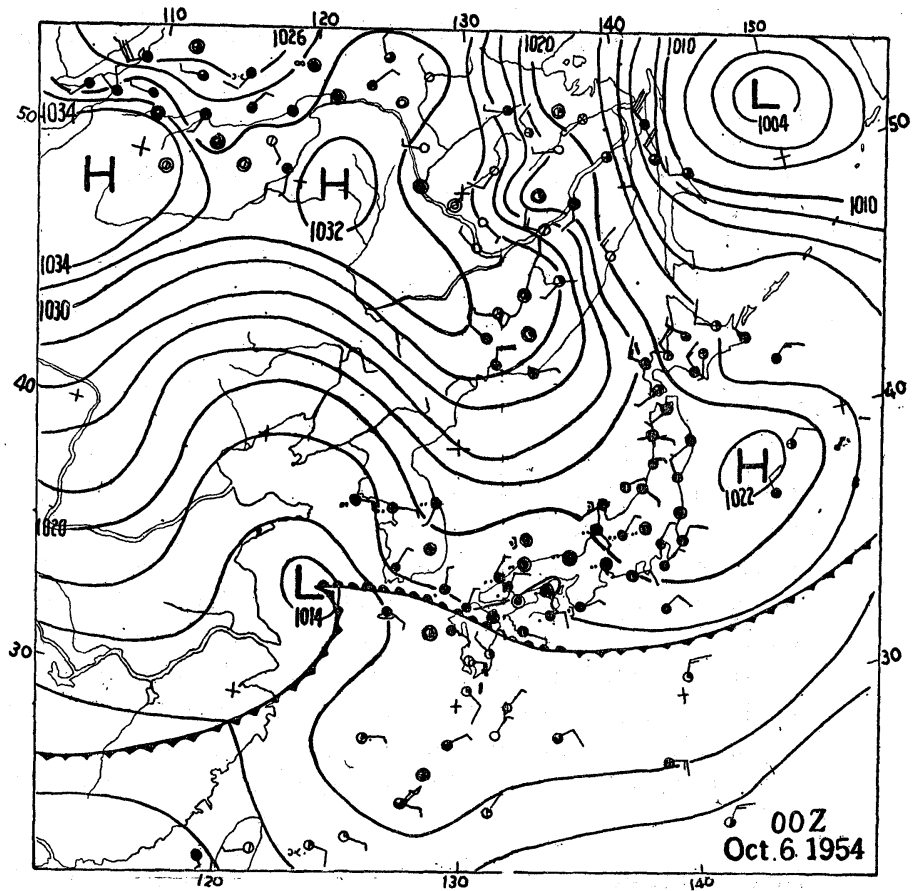

Fig. 1. Surface weather map for 6 October 1954 00GCT showing a typical Northeasterly pattern. Isobars are labelled in mb. which formed on October 1 near Formosa and crossed the Japan Sea from SW to NE to enter the Primorskaya Province (Siberian littoral province) and occluded there on October 4, an unusual coolness set in and dominated the country for about two weeks in accompaniment with continuous northeasterly wind and poor weather in the middle and southwest Japan. The surface chart on 00GCT Oct. 6 is shown in Fig. 1. The pressure pattern and the weather condition characterizing the Northeasterly situation is ideally represented in it.

The arrival of this persistent cool spell may be seen clearly in the trend of 5-day mean temperature anomaly at various stations in the Far East shown in Fig. 2. Here, the curves are arranged in downward decreasing order of the latitude of stations. As will be seen in this, the low temperature first appeared in east Siberia in the end of September, while it was still warm in Japan, and propagated southward to reach as far south as Ishigakijima (in the south of Okinawa Is.) in the middle of October.

To get a general idea of the development of pressure pattern which brought about such an unusual temperature change, 10-day mean

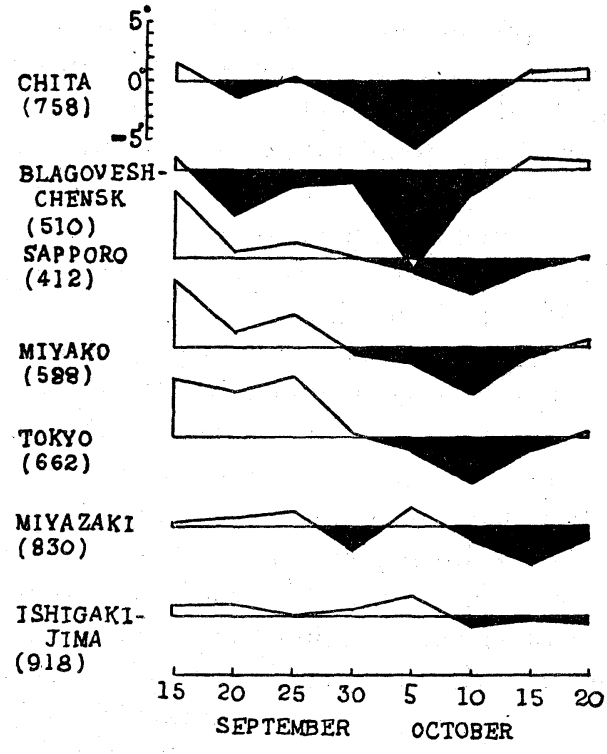

Fig. 2. Trend of 5-day mean temperature anomaly at various stations in Japan and Siberia. Temperature scale is given in degrees of centigrade in the upper left. Figures in the parentheses are index numbers of the stations. Each 5 -day period is indicated by the date in the middle of it. 

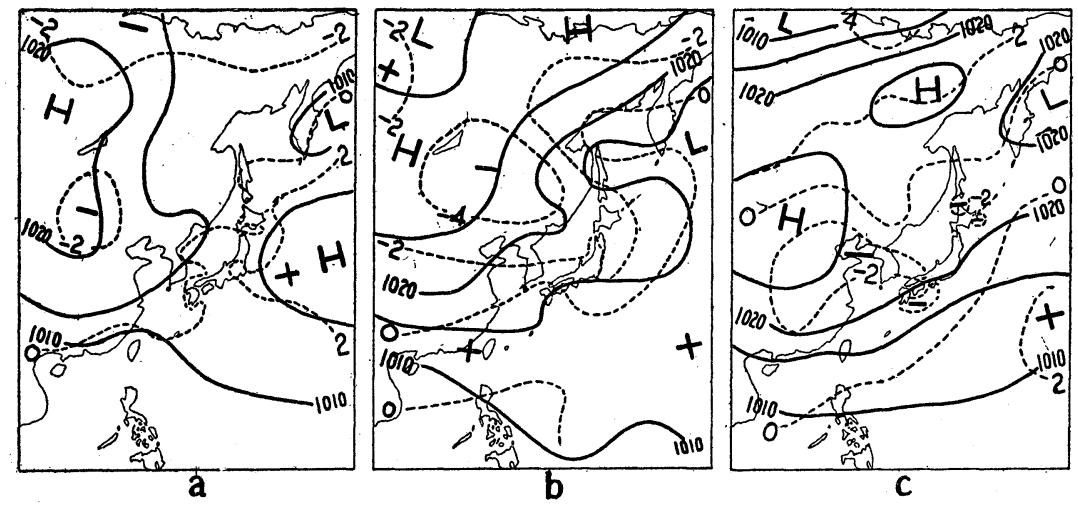

Fig. 3. Distribution of 10-day mean surface pressure and temperature anomaly for the period of Sept. 21-30 (a), Oct. 1-10 (b), and Oct. 11-20 (c). Isobars (solid) and temperature anomaly lines (dashed) are drawn $5 \mathrm{mb}$ and $2{ }^{\circ} \mathrm{C}$ apart, respectively.

surface isobars (full lines) are superimposed on the mean temperature anomaly chart (dashed lines) for each 10-day period from Sept. 21 to Oct, 20 as shown in Fig. 3 (a, b, c). These charts reveal that, in the last 10day of September (a), the warm southerly current from the Pacific high cell prevails over Japan and temperature is above normal everywhere, whereas the eastern part of the Asian Continent is covered by a vast area of below-normal temperature. Then, in the first 10-day of October (b), with the sudden retreat of the Pacific high cell, a marked wedge of high pressure extends from Manchuria eastward to north Japan, thus establishing the Northeasterly pattern of pressure field. At the same time, an extensive cold area appears to the southeast of Lake Baikal and bulges eastward to cover the whole Japan except its southwestern part. Finally, in the middle 10-day of October (c), the isobars run still in NE-SW direction along the Japanese Islands pointing to the persistence of northeasterly winds, but it is worthy of mention that they are shifted considerably southward with a concurrent movement of the center of low temperature from north Manchuria to the latitude of Korea and southwest Japan.

By what mechanism does such an intense cold-outbreak take place and how does it last for so long a period as two weeks? In the following sections this problem is attacked from the viewpoint of large scale variation in the general circulation of the atmosphere.

\section{§ 3. Development of the hemispherical pressure distribution and the westerly waves}

In order to see the characteristic features of the hemispherical pressure distribution during the period of our concern, 5-day mean $500 \mathrm{mb}$ northern hemisphere maps for the period of September 23 through October 12 are presented in Fig. 4 (a, b, c, d), where contours are drawn in solid lines each $200 \mathrm{ft}$ apart. Superimposed on them, surface mean isobars for respective 5-day periods are also entered in dashed lines for each $5 \mathrm{mb}$. These mean maps are constructed on the basis of the daily northern hemisphere charts drawn in the Forecast Section of CMO once a day for $1500 \mathrm{GCT}$. Comparative study of the two sets of lines for successive 5-day periods reveals the development of the general circulation of the atmosphere during the prolonged cold outbreak as outlined below.

In the 5-day period of Sept. 23-27 (Fig. 4a), $500 \mathrm{mb}$ contours show low pressure over the polar region with two centers, one west of Spitzbergen and the other over the Arctic Ocean at $180^{\circ}$ of longitude, contours running nearly parallel to the latitudinal lines. On the surface level, zonal character of pressure pattern is evident and the subtropical high pressure belt encircles the pole along the latitude of $35^{\circ} \mathrm{N}$. As is indicated by the zone of concentrated contour lines, the belt of westerlies contracts close to the pole and shows hardly any perceptible undulation, 


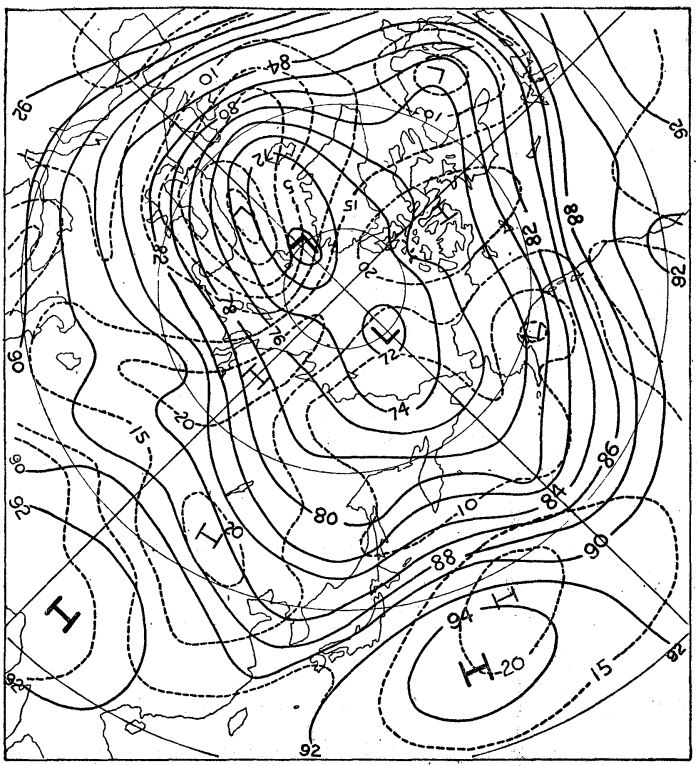

a

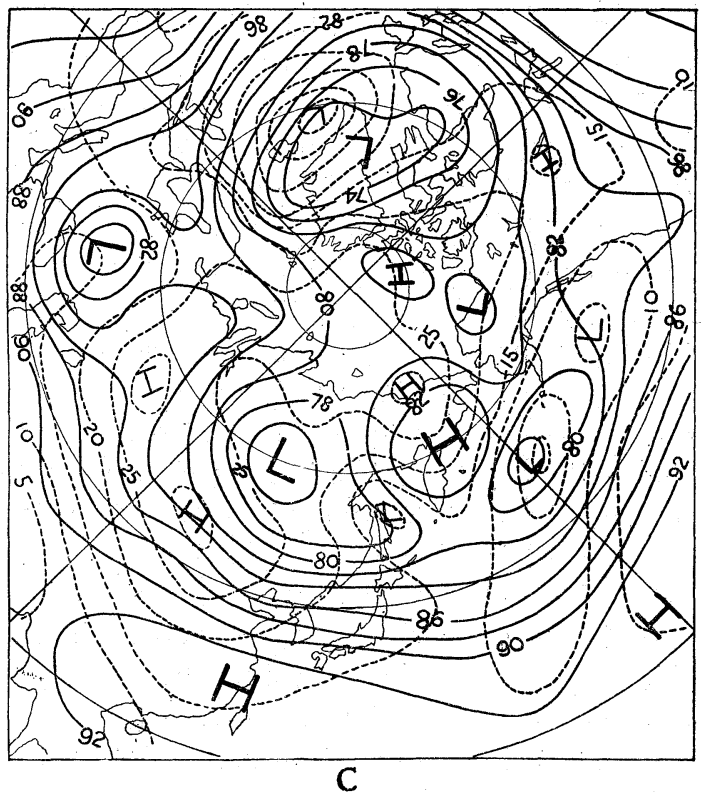

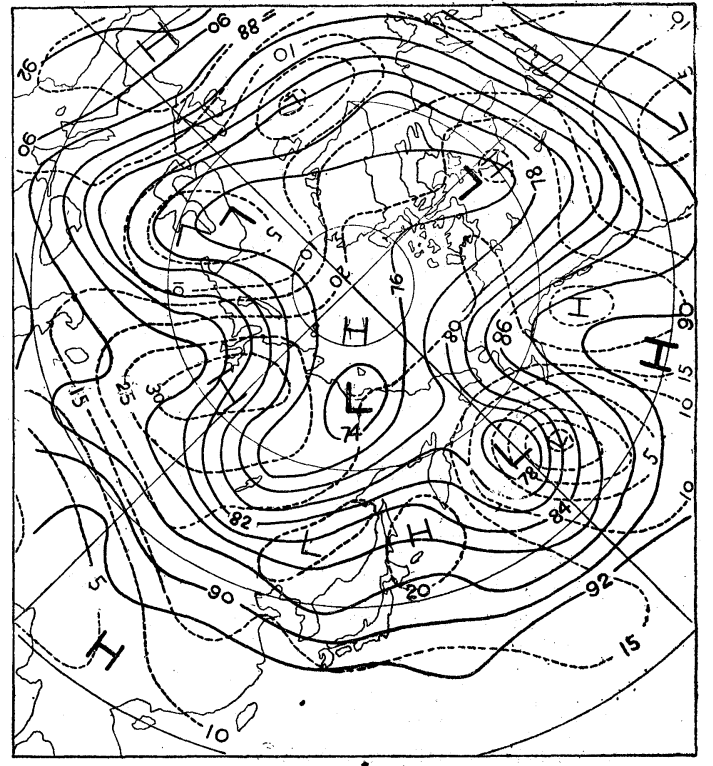

b

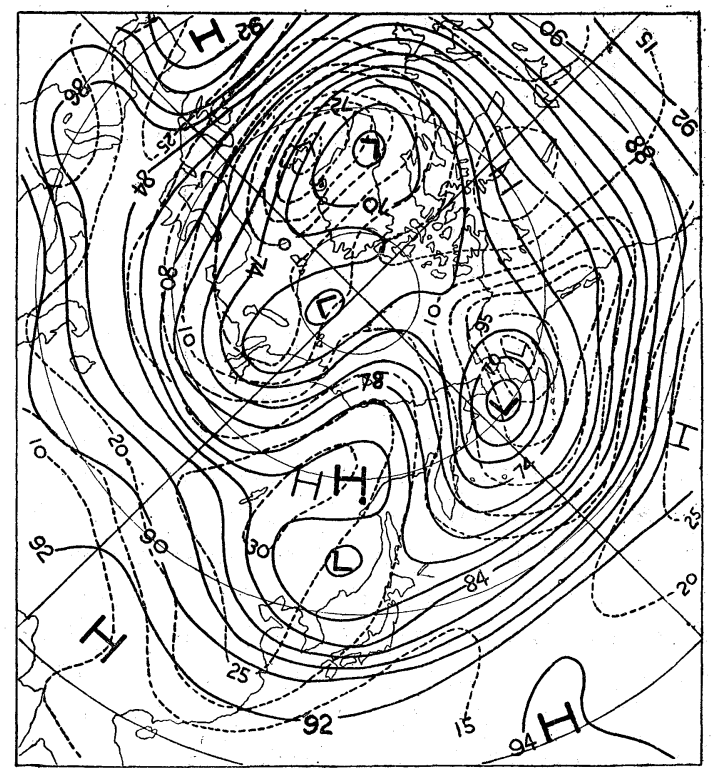

d

Fig. 4. 5-day mean $500 \mathrm{mb}$ contours (full) and surface isobars (dashed) for the period of Sept. 23-27 (a), Sept. 28-Oct. 2 (b), Oct. 3-7 (c) and Oct. 8-12 (d). Contours and isobars are drawn each 200ft and $5 \mathrm{mb}$ apart, respectively. Contours are labelled in hundreds of feet, isobars in $\mathrm{mb}$.

manifesting the characteristic features of ed southward movement. The pressure high index pattern.

Then, in the next period of Sept. 28-Oct. 2 (Fig. 4b), two striking upper level ridges and two surface high cells associated with them form in west Siberia and Alaska and the upper level low around the pole breaks into four individual vortices which show a markaround the pole begins to rise accordingly on both $500 \mathrm{mb}$ and surface levels. Corresponding to this development, the westerly current starts to meander increasing the number of the waves in it. In the Far East, it splits into two in Mongolia forming a weak double jet structure over the Japan area. As pointed 
out in the previous report [1], this is a characteristic feature of the jet stream established in connection with the "North High" situation of the surface pressure pattern and, as a matter of fact, formation of a surface high over the Okhotsk Sea is noticed in Fig. 4b. The sudden drop of temperature in Japan from the preceding 5-day period as seen in Fig. 2 can also be accounted for if we consider the change of wind direction from SW to NE caused by the anticyclogenesis to the northeast.

It is interesting to note that, of the four upper level vortices mentioned above, two are different in nature from the others. Namely, those situated over the Aleutian Is. and North Sea are both accompanied by a well-defined surface low and doubtlessly represent the final stage of frontal cyclones which have originated in middle latitudes as disturbances on the polar front and have occluded completely. In contrast with these, the vortices on the coast of Arctic Ocean in northeast Siberia and north Canada show no sign of extension to the surface level and the areas below their center are covered by surface anticylones. From the hydrostatic consideration, it can readily be surmised that they are cold vortices composed of uniform cold air mass and are in no direct connection with frontal system. As will be shown later, the cold vortex on the Siberian coast is one of the main factors responsible to the persistent cold-outbreak in the Fas East.

In the next 5-day period of Oct. 3-7 (Fig. $4 \mathrm{c}$ ), the pressure rise around the pole continues and the "polar cap" is formed on the surface level. The cold vortex of northeast Siberia moves further south to the latitude of $60^{\circ} \mathrm{N}$. The Alaskan ridge is cut off in its nothern portion and has moved westward to Kamchatka, whereas in east Europe, a cut-off low is formed over Ukraine, thus completing a typical low index character of the hemispherical pattern. It is important to note that an intense surface high is formed to the south of the Siberian cold vortex and is about to extend eastward to north Japan. Since the $500 \mathrm{mb}$ contours above it is cyclonic, the high is definitely of cold type composed of the same air mass as that of the cold vortex.
This is also evident from the tremendous temperature fall recorded at the two Siberian stations as shown in Fig. 2. It is very likely that this cold high is steered by the upper westerlies, which is very strong and nearly zonal as will be seen from the $500 \mathrm{mb}$ contours, eastward to reach north Japan and to form there the north-easterly pressure pattern. That this is actually the case is shown later by the analysis of temperature field.

Finally, in the 5-day period of Oct. 8-12 (Fig. 4d), the pressure around the pole starts to fall again both on the surface and $500 \mathrm{mb}$ level, Aleutian and Icelandic low sintensify and the subtropical high cells resume their zonal character, all indicating the transition to the high index pattern. Correspondingly, the jet stream begins to shift northward both over the Pacific and the Atlantic realizing the contraction of the westerly belt. But, on the Eurasian continent, the development is rather sluggish and the jet still remains in lower latitudes in Euroupe and in the Far East, although a new jet is already forming in high latitudes. Especially in the Far East, the cut-off high, which has retrograded from Alaska, reaches northeast of Lake Baikal to merge with the ridge of Central Asia to the southwest, thus giving rise to split of jet stream-a characteristic feature of the blocking situation. As a result, southern branch of the jet is directed southward and runs over south Japan having been displaced appreciably southward from the position in the preceding 5-day period. The cold vortex is also split into two and the one is displaced northwestward to reach the Arctic Ocean, while the other moves to east Manchuria and stays there long as a blocking low.

On the surface level, the formation of an intense anticyclone covering the extensive area of eastern Siberia and China is striking. Comparing the surface isobars with the $500 \mathrm{mb}$ contours, it is readily be noticed that this surface high is warm in its northern half in being covered by the upper level warm high, whereas the southern half is definitely consisted of cold air since the $500 \mathrm{mb}$ contours over it show a general low pressure area of the blocking low mentioned above. The unusual persistence of cold weather over the 
whole Japan area would reasonably be explained by this peculiar pressure pattern related to the blocking situation, which stagnated for nearly two weeks.

To show the blocking situation more clearly, contours of $500 \mathrm{mb}$ level are sketched once for two days from Sept. 30 Oct. 8 in a rectangular diagram as shown in Fig. 5 . In this, horizontal and vertiçal lines represent the latitudinal and the meridional circles, respectively, isolines being drawn for each
$500 \mathrm{ft}$, and the area below $18,000 \mathrm{ft}$ or above $18,500 \mathrm{ft}$ is shaded for the sake of clarity. As will readily be seen from this, cold vortices of arctic origin move down southward as the meandering of the westerlies intensifies, while the northern portions of the ridges are cut off to form independent highs and retrograde westward secluding the former in lower latitudes (Sept. 30-Oct. 4). This is the same process as described by Berggren et al. [2]. Then, on Oct. 4, the southeastern por-
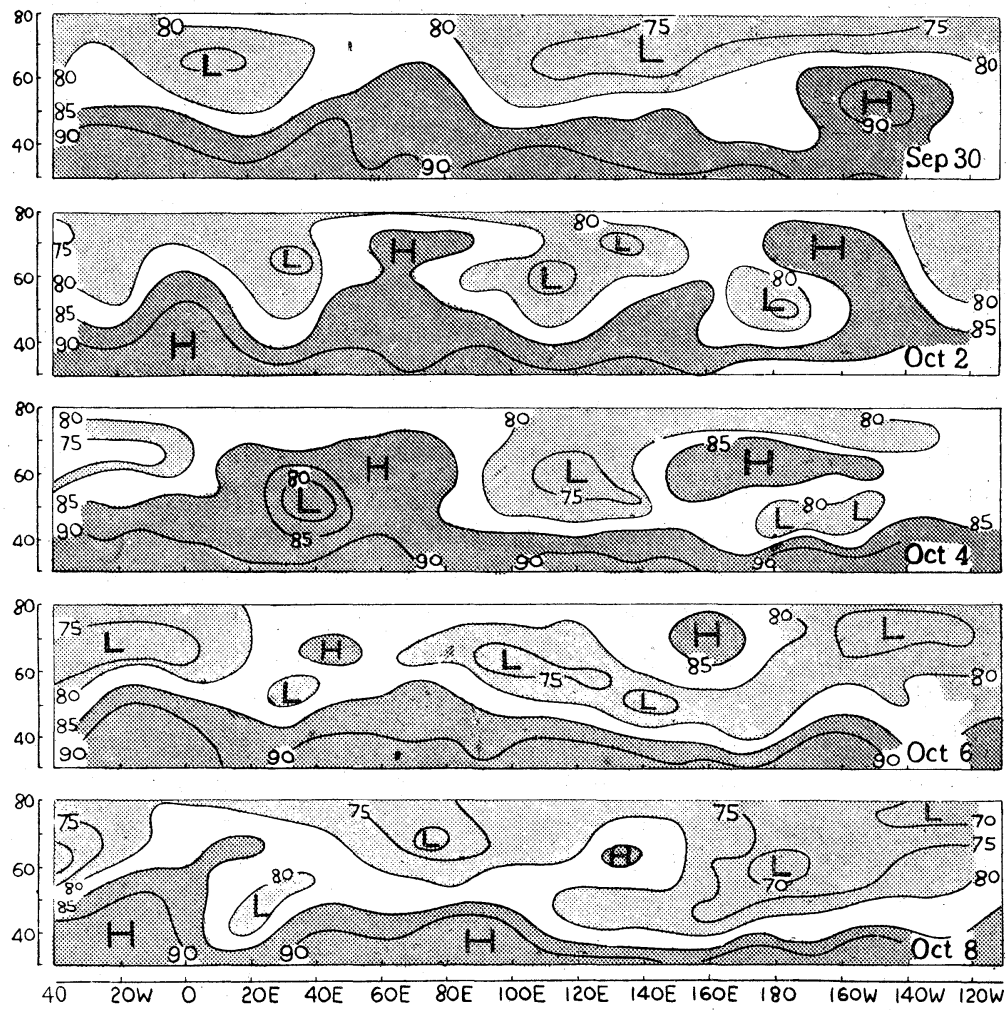

Fig. 5. $500 \mathrm{mb}$ conours represented in rectangular diagram. Ordinate and abscissa are respectively latitude and longitude. Contours are drawn each $500 \mathrm{ft}$ apart and the areas below $18,000 \mathrm{ft}$ and above $18,500 \mathrm{ft}$ are shaded.

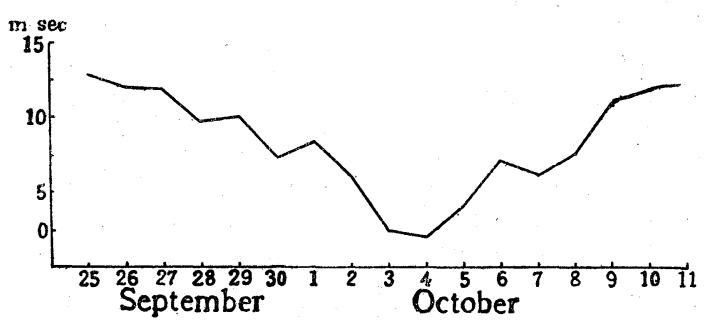

Fig. 6. Trend of zonal index in $\mathrm{m} / \mathrm{sec}$ between $45^{\circ} \mathrm{N}$ and $65^{\circ} \mathrm{N}$ computed for the longitudinal range from $40^{\circ} \mathrm{W}$ eastward to $110^{\circ} \mathrm{W}$. tion of Siberian cold vortex starts to drift eastward. Finally, on Oct. 8, the high reaches $130^{\circ} \mathrm{E}$ and joins at its southwestern edge with the ridge of lower latitudes, thus trapping a vast amount of cold air to its south between $40^{\circ} \mathrm{N}$ and $50^{\circ} \mathrm{N}$.

From the above description, one would easily rotice that the successive development of pressure pattern displayed over the Pacific and eastern Asia is good manifestations of the classical index cycle as expounded by 
Rossy and Willett [3]. Furthermore, the fact that nearly the same process took place also in Europe as will be seen in Figs. 4 and 5 suggests the global character of the decline of westerly speed. As a matter of fact, the trend of the zonal index between latitudes of $45^{\circ} \mathrm{N}$ and $65^{\circ} \mathrm{N}$ computed for the longitudinal range from $40^{\circ} \mathrm{W}$ eastward to $110^{\circ} \mathrm{W}$ shows a marked decrease from Sept. 25 to Oct. 4 and thereafter a rapid increase to the initial level till Oct. 11 (Fig. 6).

Consequently, the cause of the cold-outbreak may be attributed to the southward movement of the cold vortex from the polar region to eastern Siberia in the process of hemispherical decline of the zonal index. The establishment of the Northeasterly patterns may be easily accounted for by the
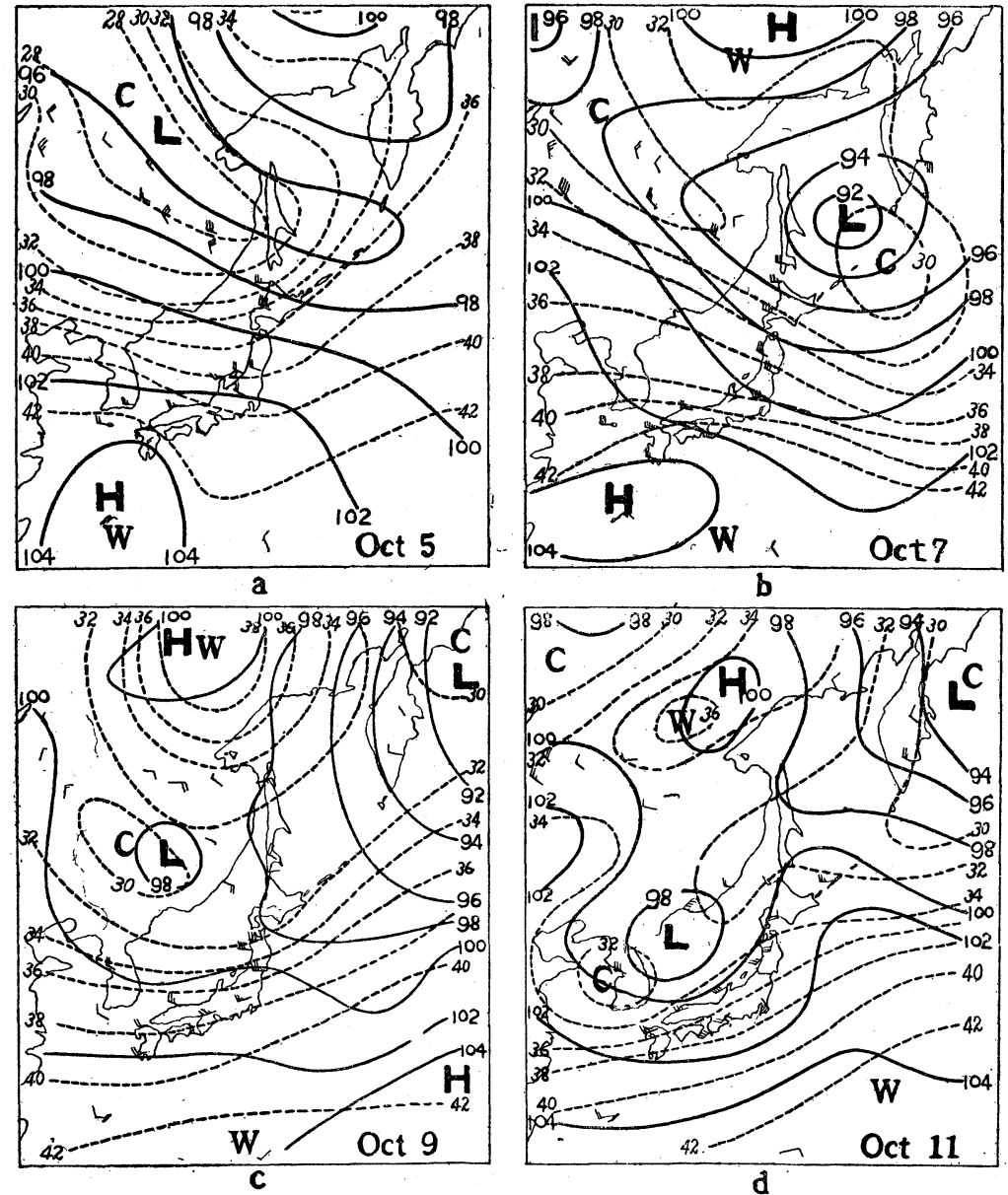

Fig. 8. $700 \mathrm{mb}$ contours (full) and $850-500 \mathrm{mb}$ thickness lines (dashed) for 1500 GCT of the day as indicated showing the cold air advection. $700 \mathrm{mb}$ wind observations are also entered in the usual symbol. 
advection of cold air due to the upper westerlies, whereas its persistence may be understood if we notice that a great amount of cold air mass was trapped by the warm blocking high and stagnated while the blocking situation lasted. The same applies to the very similar case of cold outbreak in the end of January, 1954, which has been reported previously [4].

\section{$\S 4$. Cold air advection to north Japan as a cause of the Northeasterly situation}

The movement of cold vortex revealed by the study of 5-day mean maps can be traced also on the daily basis except for the period before Oct. 3, when exact location of the low pressure center is difficult due to lack of data. In Fig. 7, the position of the centers of vortices fixed on daily $500 \mathrm{mb}$ map for $1500 \mathrm{GCT}$ is indicated by black circles, the figures there attached being the date. The position of the center of the retrogressive cut-off high is also shown by white circles.

As will be seen in this, the vortex which has moved south until 4 to reach east of Lake Baikal, split into two on 5, when the zonal index reached minimum. (See Fig. 6). Then, in the following stage of increasing zonal index, one part starts to migrate northwestward increasing in intensity and on Oct. 14, returns to its original region of the Arctic, while the other moves ESE, crosses Sakhalin on Oct. 7 and dissipates to the east of the Kurile Is. on Oct. 9. It is interesting to note that, after the passage of the latter to the north Pacific, two low pressure centers appear one after another in Manchuria and north Korea. As will be shown presently, they are cold vortices formed in the cold air, which is trapped by the blocking high, and their formation in lower and lower latitudes corresponds to the gradual southward movement of the cold air.

In order to see the development of temperature field in relation to the pressure pattern, $850-500 \mathrm{mb}$ thickness chart representing the temperature distribution in the lower half of the troposphere, is constructed once for two days during the period of Oct. 5-11, when Japan is dominated by abnormal coolness, and is superimposed upon $700 \mathrm{mb}$ map as shown in Fig. 8 (a, b, c). In this, equal thickness lines are drawn in broken lines, contours in full, both for each $200 \mathrm{ft}$, and winds on the $700 \mathrm{mb}$ level are entered in the usual symbol.

Looking at the chart for Oct. 5 , one would immediately notice that the cold vortex over eastern Siberia is actually composed of cold air. Remarkable is the strong cold air advection taking place over the Primorskaya Province, northern part of the Japan Sea and north Japan. The surface high pressure wedge peculiar to the Northeasterly pattern must doubtlessly be formed by it through an intense subsidence and the consequent decrease of relative vorticity in a shallow layer next to the ground. One may compare the surface pressure pattern (Fig. 1) with Fig. 8a; parallelism of the axes of cold air advection and of the high pressure wedge is striking. It can also be seen from Fig. 8 that, with the arrival of cold air in north Japan, the thickness lines become compact to the south suggesting the increase of meridional temperature gradient or the frontogenesis in zonal direction. Then, if the cold air advection of this kind is sufficiently intense and persistent as it actually is in the present case a sharp frontal zone should be formed and stagnate along the southern margin of the cold air as long as its supply continues. The peculiar nature of the stationary front, which forms along the Pacific coast of Japan in case of the Northeasterly situation and brings about poor weather in the middle and south of the country, may be explained by this process.

In the following period, as the cold vortex crosses the Okhotsk Sea and passes away to the north Pacific, the area of cold advection is displaced gradually to lower latitudes as will be seen in Fig. 8b, c and reaches finally southwest Japan and the Yellow Sea on Oct. 11 (Fig. 8d). In this process of southward displacement of cold air, the formation of the new cold vortices mentioned earlier seems to play a major role: a new area of strong cold advection is noted on Oct. 9 over Manchuria and north Korea to the southwest of a cold vortex in east Manchuria, and on Oct. 11, a similar area over west Japan and Yellow Sea, again to the southwest of another vortex in Japan Sea. Presumably, these cold vortices are formed to the south of their predecessor 


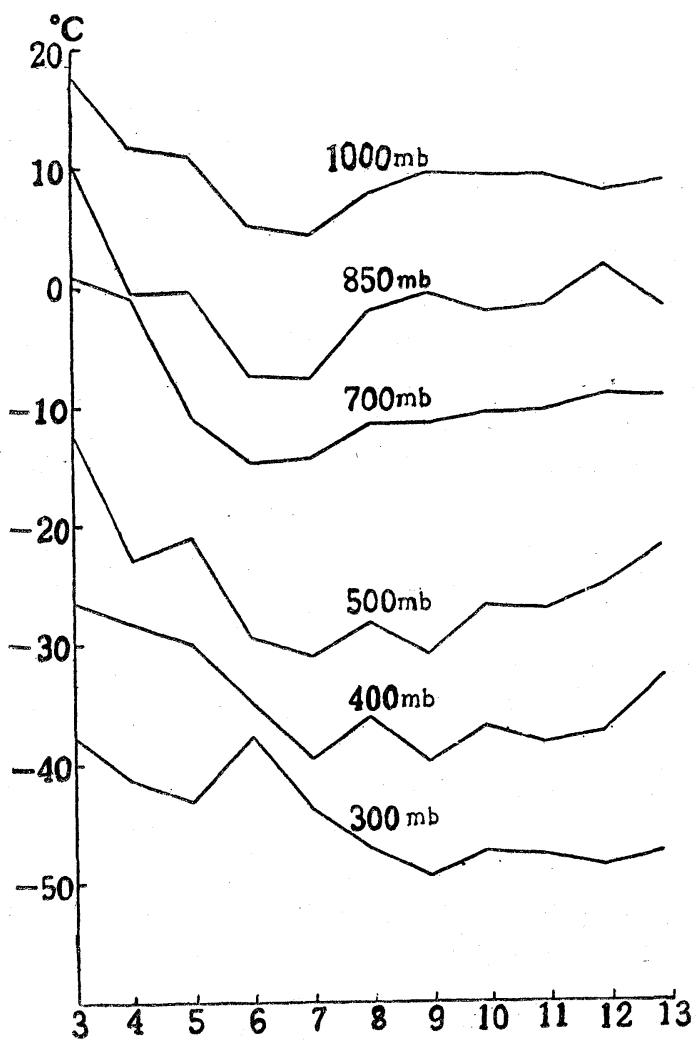

Fig. 9. Temperature trend on various levels from 1,000 to $300 \mathrm{mb}$ over Wakkanai (401) for the period of Oct. 3-13.

to the north mainly due to the concentration of the solenoid generated by the cold air advection, and then in their turn touch off a new cold wave thus enabling the invasion of the cold air mass to lower latitudes. In this way, the great store of cold air accumulated in Manchuria and east Siberia is discharged little by little until it is exhausted.

It may be worthwhile to add here that the

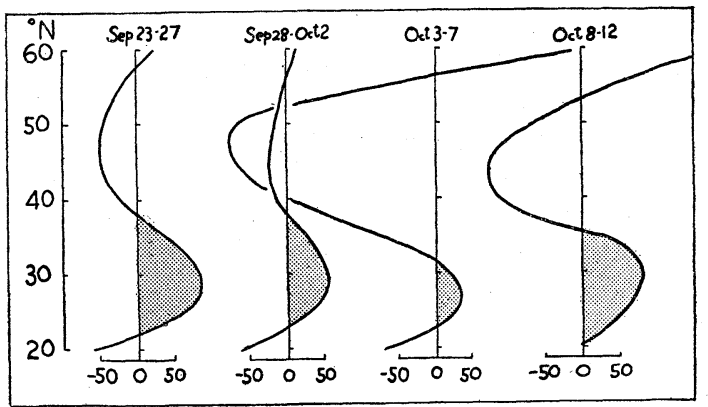

Fig. 10. Meridional profiles of the 5-day mean height anomaly of $500 \mathrm{mb}$ level for the longitude range of $90^{\circ} \mathrm{E}-180^{\circ}$. Area of positive anomaly in middle latitude is shaded. verticl extent of the cold air is very large. Curves in Fig. 9 shows the temperature trend on various levels from $1,000 \mathrm{mb}$ to $300 \mathrm{mb}$ over Wakkanai for the period of Oct. 3-13. The reason for choosing this station is that, being located at the northern tip of Hokkaido, it would represent the best the structure of fresh cold outbreak. As can be readily seen in this, a remarkable temperature fall is recorded from October 3 to 7 at all levels below $400 \mathrm{mb}$, the amount of temperature decrease being the largest in the middle troposphere $-18^{\circ} \mathrm{C}$ within four days at $500 \mathrm{mb}$ level! From this, it is concluded that the thickness of the cold air mass is extensive filling nearly the whole troposhere and the old theory of attributing the anticyclogenesis off the coast of northeast Japan to cooling from the sea surface below is perfectly untenable at least in the present case.

In the above discussions, it is made clear that the air mass responsible to the cold-outbreak is formed in a great cold vortex of Arctic origin and is advected from east Siberia or north Manchuria eastward to north Japan. It may then be asked why it does not invade southward deep into the continent to flood over the whole Far East as it commonly does after the passage of intense troughs; some agency must be acting as a barrier to the outbreak of polar air and deflect it eastward. This may be sought in the characteristic feature of pressure pattern.

In September 1954, the subtropical high pressure belt was very strong to the south of Japan, thus giving rise to a prolonged summer weather over the country as stated in Section 2. This is also indicated by the northward deviation of typhoon tracks from the seasonal normal. This tendency continued, though diminishing in strength, in the beginning of October as can be seen in Fig. 10 , where the meridional profiles of the 5-day mean height anomaly of $500 \mathrm{mb}$ surface for the longitude range of $90^{\circ} \mathrm{E}-180^{\circ}$ are shown. From this, it seems quite likely that the cold vortex moving down from the north is checked of its southward trend by the high pressure belt along $30^{\circ} \mathrm{N}$ (shaded area in the diagram) and steered by it. In other words, as soon as the cold air mass reached the latitudes of $40^{\circ}-45^{\circ} \mathrm{N}$, it was drifted eastward rapidly by 
the westerly wind prevailing there, the speed of which must have been greater than normal as indicated by the steep gradient of the $500 \mathrm{mb}$ height anomaly. In this way the coldout-break appeared over north Japan as a sharp wedge-like advection forming the Northeasterly pattern.

\section{$\S$ 6. Conclusions}

In an attempt to make clear the mechanism of persistent cold outbreak in Japan, a case study is made on the weather sequence displayed from the end of September to the middle of October, 1954. The result obtained may be summarized as follows:

(1) In the end of September 1954, a worldwide decline of zonal index took place and the circumpolar vortex thus far contracted around the pole expanded and split into individual vortices to move southward. One of these displaced to northeast Siberia is a pure cold vortex consisted of a uniform air mass and is not related to frontal systems.

(2) When the vortex reached to the east of Lake Baikal, it was checked of its southward motion and steered eastward by the strong westerly wind. In consequence of this, cold air was advected to the north of Japan in a sharp wedge along the southern margin of the vortex and formed to its immediate south a well-defined surface anticyclone through intense subsidence.

(3) On the other hand a cut-off high originated from the Alaskan ridge reached northeast Siberia and stagnated there as a blocking high. As a result, a great mass of cold air brought about by the cold vortex was trapped by it over Manchuria and was discharged eastward little by little resulting in the persistent coolness over Japan.

(4) The cold advection in north Japan is extensive in thickness filling nearly whole troposphere. To its south new cold vortices are formed successively and reenforce the cold advection to reach lower and lower latitudes. The southward displacement of cold air is realized in this process.

(5) The steep temperature gradient to the south of the wedge-shaped cold air advection results in the formation of the stationary front along the Pacific coast of Japan. It stagnates until the great store of cold air over the continent is exhausted.

Derived from the analysis of only one case, these conclusions may not apply to the persistent cold-outbreak in general. Furthermore, the three-dimensional analysis of the cold air advection and the related frontogenesis, which is not undertaken here, would be indispensable to make clear their detailed mechanism. In this sense the present study is incomplete and shall be elaborated in the future. But since it revealed at least the significance of the global decline of westerly speed to the cold-outbreak, the writer hopes it serves as a preliminary investigation to clarify the large scale weather development in the Far East as related to the general circulation of the atmosphere.

\section{Acknowledgement:}

The writer is greatly indebted to $\mathrm{Mr}$. K. Mohri, Forecast Section of CMO, who read the manuscript and gave him valuable suggestions.

\section{References}

1. Suda, K. and Asakura, T. (1955); A Study on the Unusual "Baiu" Season in 1954 by Means of Northern Hemisphere Upper Air Mean Charts, Journ. Met- Soc. Japan, 33, No. 6.

2. Berggren, R., Bolin, B. and Rossby, C.-G. (1949); An Aerological Study of Zonal Motion, Its Perturbations and Break-Down, Tellus Vol. 1, No. 2.

3. Rossby, C.-G. and Willet, H. C. (1948): The Circulation of the Upper. Troposphere and Lower Stratosphere, Science, 108.

4. Suda, K. (1955): On the Cold Wave of Janaury 1954 in the Far East, Geofisica Pura e Applicata, Vol. 32, pp. 159-169. 